\title{
National Programming Competitions, Team Selection and Training in Hungary
}

\author{
László NIKHÁZY1, László ZSAKÓ2 \\ ${ }^{1}$ Doctoral School, Faculty of Informatics, Eötvös Loránd University, Budapest, Hungary \\ ${ }^{2}$ Faculty of Informatics, Eötvös Loránd University, Budapest, Hungary \\ e-mail:nikhazy@inf.elte.hu,zsako@caesar.elte.hu
}

\begin{abstract}
Programming competitions for middle and high school students have a long tradition in Hungary, the first national competition dates back to 1985 , and our country has been participating in the International Olympiad in Informatics (IOI) from the very beginning. This paper presents the current situation and challenges of Hungarian nationwide programming contests, national team selection, and training system.
\end{abstract}

Keywords: programming competition, informatics education, training, IOI, Hungary.

\section{Introduction}

In Hungary, already in the early eighties, regional programming competitions were organized for middle and high school students. As a result of the school computer program and the evolving microcomputer clubs, the Nemes Tihamér Competition was established in 1985, being the first national programming competition. In the first year, approximately 1000 students entered the competition. The number of participants then gradually increased, in recent years there have been around 2500-3000 students taking part, from 200-250 schools regularly.

Since then, numerous other informatics competitions have come into existence. Not only in competitive programming, but also in robotics, application development, application usage, and computational thinking. We provide an overview of them in the next chapter of this article. We describe the details of the programming category of the Nemes Tihamér Informatics Competition (NT) and the National High School Competition in Informatics (OKTV) in the third chapter.

Hungary has participated in the IOI every year since its start and won 13 gold, 31 silver and 44 bronze medals in total. Our country hosted the competition already once in 1996 and we are going to host it for the second time in 2023. It will be a special year for the Hungarian computer science community, we celebrate the $120^{\text {th }}$ birth anniver- 
sary of John von Neumann, the greatest Hungarian figure in the theory of computing, who is often regarded as the foremost mathematician of his time.

Hungary was one of the initiators of the Central European Olympiad in Informatics (CEOI), and our team participated every year since the start of the competition in 1994. The CEOI was held in Hungary four times already (1995, 2001, 2005, 2012), and we are hosting the competition this year, in 2020, in the city of Nagykanizsa. Hungarian contestants have also achieved excellent results at the CEOI, they have won 2 gold, 14 silver and 42 bronze medals in total. Our country took part in all three editions of the European Junior Olympiad in Informatics (EJOI) (Manev \& Yovcheva, 2017) so far, and we are also going to participate in the European Girls' Olympiad in Informatics (EGOI) starting from its kick-off in 2021.

The IOI and CEOI team selection process have long traditions, the students qualify through an extensive competition, which we describe in the fourth chapter. In recent years, a similar, but shorter competition has been organized for the EJOI team selection. In the fourth chapter, we also provide an overview of the training and team preparation system currently in Hungary. Finally, in the fifth chapter, we write about the challenges we are facing at present and our plans for the future.

\section{National Competitions in Informatics}

There are several national competitions in informatics for primary, middle, and high school students, not limited to computer programming. We categorize them in the table below. Their websites are listed at the end of the article.

We would like to mention that in some cases the categorization is not straightforward. For example, a couple of application development competitions have some algorithmic challenges and similar input-output testing as the IOI-style competitions, which focus on algorithms and data structures. Furthermore, many of the first rounds of IOI-style competitions test algorithmic thinking with tasks on paper, so we put the first rounds separately to the corresponding category. In the next chapter, we focus on IOI style national competitions, which are the first steps towards the national team selection. We provide a very short description of the other competitions here.

The Nemes Tihamér Online Programming Competition is a five-round online contest which is a practice and preparation opportunity for the onsite competition.

The Programming Contest of the University of Debrecen is a team competition for high school students similar to the International Collegiate Programming Contest (ACM ICPC).

The Izsák Imre Gyula Complex Science Competition is a multi-discipline contest in mathematics, physics, and informatics. It involves a programming contest and the winner of that category is invited to the IOI Qualification Competition.

The Logo National Informatics Competition is organized in five age groups for elementary, middle, and high school students. The main topic is turtle graphics, except for category 0 , which is a robot programming contest for elementary school pupils. 
Table 1

National informatics competitions in Hungary

\begin{tabular}{|c|c|}
\hline \multirow[t]{5}{*}{ IOI-style } & Nemes Tihamér Informatics Competition (programming category) \\
\hline & National High School Competition in Informatics (programming category) \\
\hline & Nemes Tihamér Online Programming Competition \\
\hline & Programming Contest of the University of Debrecen \\
\hline & Programming category of the Izsák Imre Gyula Complex Science Competition \\
\hline \multirow{3}{*}{$\begin{array}{l}\text { Algorithmic } \\
\text { thinking }\end{array}$} & Logo National Informatics Competition \\
\hline & First round of the Nemes Tihamér Informatics Competition \\
\hline & First round of the National High School Competition in Informatics \\
\hline $\begin{array}{l}\text { Computational } \\
\text { thinking }\end{array}$ & e-Hód Competition (Bebras) \\
\hline \multirow[t]{5}{*}{ Robotics } & First ${ }^{\circledR}$ LEGO ${ }^{\circledR}$ League \\
\hline & World Robot Olympiad ${ }^{\mathrm{TM}}$ \\
\hline & Category 0 of the Logo National Informatics Competition \\
\hline & Robot Sumo Competition \\
\hline & Robot Programming National Team Contest \\
\hline \multirow{5}{*}{$\begin{array}{l}\text { Application } \\
\text { development }\end{array}$} & Neumann János Talent Search Software Product Competition \\
\hline & Programmers’ National Dusza Árpád Memorial Competition \\
\hline & ProgRace Programming Contest \\
\hline & PENDroid High School Competition \\
\hline & $\mathrm{B}^{3}$ - Bakonyi Bitfaragó Championship \\
\hline \multirow[t]{3}{*}{ Application usage } & Nemes Tihamér Informatics Competition (application category) \\
\hline & National High School Competition in Informatics (application category) \\
\hline & Kozma László National Informatics Competition \\
\hline
\end{tabular}

The Bebras challenge is called e-Hód Competition in Hungary. It is gaining huge popularity, in 2019 there were more than 27 thousand participants from 202 schools across all age groups.

There are regional and national rounds in Hungary of the well-known international robot programming competitions, the First $^{\circledR}{ }^{\circledR}$ LEGO $^{\circledR}$ League (FLL), and the World Robot Olympiad ${ }^{\mathrm{TM}}$ (WRO). The FLL is held since 2004, while the WRO was first organized in Hungary in 2014, and our country hosted the WRO 2019 Final in the city of Győr.

In the Robot Sumo Competition, two-person teams have to build LEGO ${ }^{\circledR}$ robots that fight against each other like the sumo sport. In the Robot Programming National Team Contest, teams of two or three middle school students compete in designing and programming a LEGO ${ }^{\circledR}$ robot to solve challenges on a field.

In the Neumann János Talent Search Software Product Competition there is no task, but contestants can present their work to the jury, and get prizes in multiple categories: applications, games, hardware control, computer graphics, animations, and computeraided design. 
In the Programmers' National Dusza Árpád Memorial Competition every team has to write an application solving the same problem. It has a regular PC software development, web development, and mobile application development category as well.

The ProgRace Programming Contest is organized by the University of Pécs for both high school and university students. Teams of two or three contestants can enter using any programming language. They have to solve an open-ended challenge from different topics each year.

The PENDroid High School Competition is an Android app development competition organized by the Nagykanizsa Campus of the University of Pannonia. There is a qualification round that has educational purposes, and a final round, where the teams should bring an Android game written by them and they also have to solve a task onsite.

The $\mathrm{B}^{3}-$ Bakonyi Bitfaragó Championship is hosted by the Faculty of Information Technology of the University of Pannonia. Teams of high school students compete in several categories, and the tasks usually involve web programming.

The Nemes Tihamér Informatics Competition and the National High School Competition in Informatics have an application usage category, where contestants need to solve tasks in office applications. Tasks involve documents, spreadsheets, presentations, static web pages, database management, and image editing.

The Kozma László National Informatics Competition is a team contest for middle and high school students, where participants create solutions to project-based tasks in office applications.

\section{The Nemes Tihamér Programming Competition}

The NT competition and the OKTV are the most prestigious programming contests in Hungary, which also serve as the primary entrance to the qualification competitions of all the international Olympiads. NT is organized by the cooperation of the John von Neumann Computer Society (NJSzT) and the Eötvös Loránd University (ELTE), and the OKTV is organized by the Education Office of Hungary together with ELTE. They have the same format, same submission system, and most members of the scientific committee work on both competitions.

As mentioned above, the NT competition was first organized in 1985. It had two rounds for 9 years, the first round was written on paper in schools, and the second round held at ELTE, where competitors usually had to write a program for a single major task, in BASIC, Pascal, or possibly C of their choice. From 1990, the $9-10^{\text {th }}$ grade $(15-16$ years old) students are given a different set of tasks than the $11-12^{\text {th }}$ graders (17-18 years old). From 1994, the competition was expanded with another category, students from the $5-8^{\text {th }}$ grade (11-14 years old). In 2003 , the third age group $\left(11-12^{\text {th }}\right.$ grade) of the NT competition has got the official status of the National High School Competition in Informatics (OKTV). A few years ago, a parallel category was introduced for the $11-12^{\text {th }}$ grade students, the age group 3 of the NT competition, where students can compete who are not eligible to enter the OKTV, together with the contestants who do not meet the very strict limit for advancing in the OKTV. 


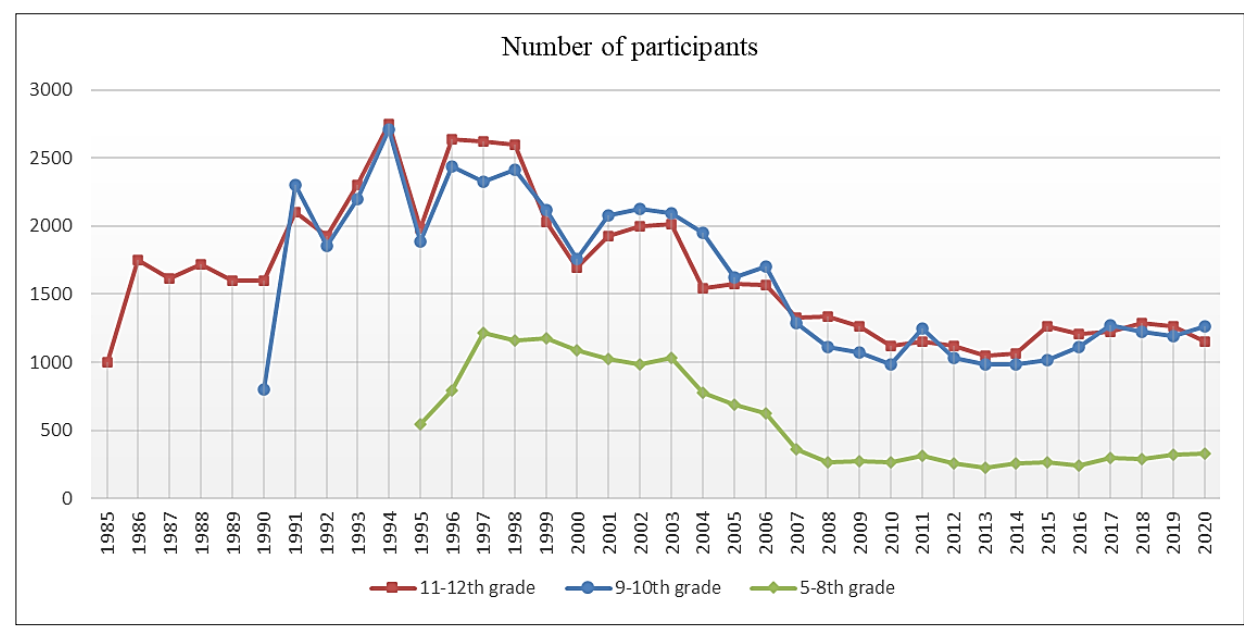

Fig. 1. Number of participants yearly in the Nemes Tihamér Competition.

An online judge system has been used at the competition in recent years, which was developed for CEOI 2012. Before that, contestants had to hand in their solution programs at the end of the contest (through the local network, or floppy disks), and they were evaluated afterward with testing scripts.

At present, there are three stages of the competition, a school round, a regional round, and a final. All rounds are held at the same time for all contestants, with the same, centrally composed task sheet. In the first round, everyone writes the contest at their own school, the second round is organized by selected schools in each region. The final takes place in 3-5 cities in Hungary since the online judging makes it easy to organize the contest in different locations. A few years ago, everyone had to travel to the capital. It is still the case for the OKTV category, as it is regulated by the ministry.

\subsection{School Round}

The first round usually takes place in early November. No computers are used at this stage, students have to solve 4-8 tasks on paper. (More precisely, the children in the lowest age group can choose to solve one task on the computer, but the rest of them are on paper.) The tasks are designed to test algorithmic thinking and understanding topics in computer science, particularly, but not limited to algorithms, data structures, and programming. The algorithms are described with a Hungarian pseudocode syntax close to natural language. There can be problems from other areas of computer science, like formal grammars, automatons, logical circuits, functional and logical programming languages, etc. In this case, the task description contains enough information about the topic to solve the problem, since these areas are not taught in the school. These problems test understanding new concepts, besides analytical thinking. 
We find it beneficial to have such a round, because (1) it promotes computational thinking, (2) students can enter without knowing a programming language, and (3) it provides the same circumstances for everyone, no matter how equipped their school is. We can reach out to a lot more students allowing them to enter without experience in computer programming, and thus their talent in this field can be discovered.

\subsection{Regional Round}

The second round is typically held in January with around 600 competitors altogether in the three age groups. Students have to solve IOI-style tasks on the computer. Tasks are assembled by the jury in a way that the best contestants can be selected based on the results, while everyone should have some sense of achievement. In the second and third age group (grades 9-12) there are 5-7 tasks for 5 hours, while in the first age group (grades 5-8) there are 3-4 tasks for 3 hours.

Contestants can submit their code multiple times in the online judging system, and it gets scored instantly using input-output testing. The submission with the maximum score is considered. The score for a task is calculated as the sum of the scores for the test cases passed, similarly as the IOIs before 2005 (Verhoeff, 2009). Each test case has an assigned score that can vary. If there are multiple expected outputs (e.g. the optimum value and the way to achieve it) the solution to them can be scored separately. We create subtasks by indicating the number of points that can be achieved with smaller limits or more specific constraints than the general ones in the task description. The time limit varies depending on the task, the most typical values are between $0.2-0.6$ seconds.

There is a wide variety of programming languages allowed: $\mathrm{C} / \mathrm{C}++$, Java, $\mathrm{C} \#, \mathrm{Py}-$ thon, Pascal, and Visual Basic. It remains a challenge for the task writers to achieve that the expected solutions meet the same time limit in all languages, while less optimal solutions should not pass in any language. But even like this, every language has its advantages or disadvantages for certain tasks. Contestants need to be aware of this issue when choosing the programming language. In fact, they can choose different languages for each task.

\subsection{Final Round}

The final regularly takes place in March. There are 40-60 participants in the first age group, $80-100$ in the second age group, and 50 in the OKTV category plus $30-50$ in the third age group. The final has the same format as the second round, but the problems are more difficult, more advanced topics are included. The tasks are designed to make a difference between the very best students as well. The contest duration is 6 hours for the second and third age group, and 3 hours for the first age group. The number of tasks is about the same as the second round.

The first 10-15 students of each age group of the NT competition are awarded a book. Contestants in the first 3 places of the OKTV get awards, and a so-called Tal- 
ent Passport that provides entrance to talent education programs during their university studies, and the first 30 students get extra points for their application to universities. The best contestants in each category get invitations to the Qualification Competition for International Olympiads.

\subsection{Topics of the Competition}

The topics of the problems in the regional and final round are a subset of the IOI Syllabus (Verhoeff, Horváth, Diks, \& Cormack, 2006). We are in the process of creating a similar document called NT Syllabus (Nikházy, 2019) to specify exactly what contestants need to know and thus help them and their teachers in preparing for the contest. Another goal of the syllabus is to provide guidelines for task setters in creating appropriate tasks. It contains the required knowledge for each age group of the national competition. For the IOI team selection competition, the IOI Syllabus fills this role. To create the syllabus, we examined problems of the last 5 years and created statistics about the topics appearing in problems of the regional and final round. In the following, we provide a brief overview of the topics by age group.

The problems for $5-8^{\text {th }}$ grade students essentially do not include complex "textbook" algorithms to be mastered in advance. About $65 \%$ of the tasks can be solved using the so-called patterns of algorithms (Szlávi \& Zsakó, 2008). These are simple algorithm templates that students can use in many cases without their awareness, for example, maximum selection, linear search, counting, filtering. Roughly $35 \%$ of the tasks require the use of some more advanced algorithmic strategy, for example, greedy algorithms, dynamic programming, and the two pointers technique.

In addition to the above-mentioned topics, graph algorithms appear in tasks for $9-10^{\text {th }}$ grade students and this is a major change compared to the first age group. According to the statistics, about $30 \%$ of the problems include graphs, which means that there is usually at least one such task in the regional round and two in the final. There is much more emphasis on dynamic programming (DP) than for the younger students. Problems in enumerative combinatorics frequently appear in the competition because students acquire the necessary mathematics knowledge at this age. Simulation is an important technique, the difficulty of such tasks lies in the complex implementation.

There are some significant enhancements in the topics for the $11-12^{\text {th }}$ grade students compared to younger ones. More advanced graph algorithms are required, like strongly connected components, articulation points and bridges, Eulerian path, shortest paths, and minimum spanning tree in weighted graphs. (Weighted graphs are included for the second age group, too, but they appear less frequently.) There is a completely new domain, geometric algorithms, which often provide the most difficult problems. Utilizing advanced data structures like the priority queue (heap), the set and map from the standard library are required to perform successfully in this age group. In conclusion, we can say that the topics of the OKTV are a subset of the IOI Syllabus with only some of the hardest algorithms and data structures excluded. 


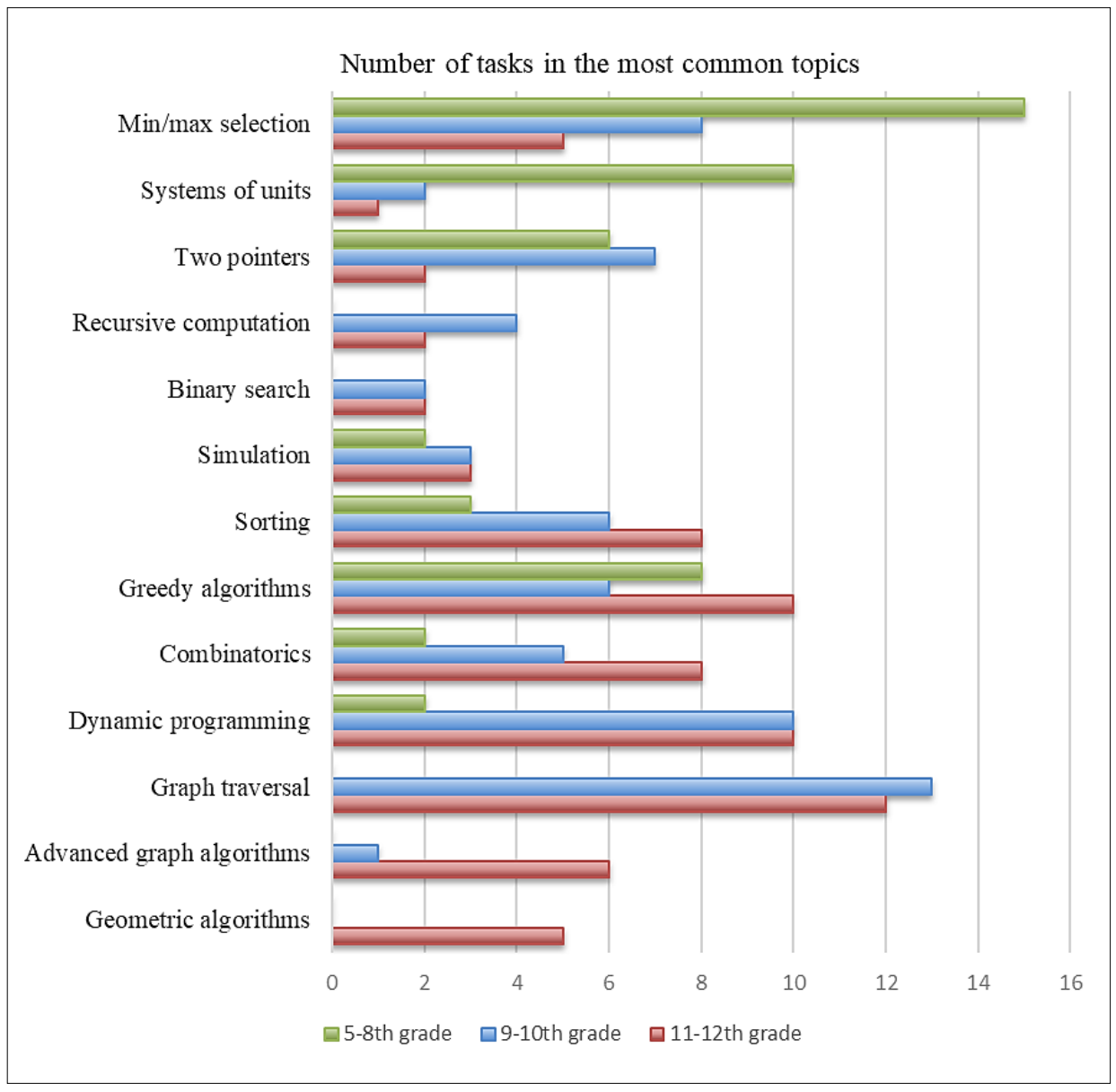

Fig. 2. Appearance of the most significant topics in the last 50 tasks of each age group.

\section{Team Selection and Training for the IOI, CEOI, and EJOI}

\subsection{Qualification Competition}

There is an intensive and comprehensive Qualification Competition (QC) to select the Hungarian team for the IOI and CEOI. There are 6 rounds, each round has 3 problems for 3 hours, which means there are 18 problems in total. Usually, two rounds are held on one day, so there are 3 competition days. The topics of the competition are the same as at the IOI, the IOI Syllabus is used as the definitive guide to propose tasks. In each round, there is one problem that tests knowledge of some standard algorithm or a typical problem-solving strategy, one intermediate, and one hard task which are similar to CEOI 
and IOI tasks. For evaluation, the same system is used as the national competition, but we try to put emphasis on subtasks by creating more subtasks for one problem and also grouping more test cases into one test file when we find it necessary.

The 4 students of the IOI team and the 4 students of the CEOI team are selected based on their total points in the 6 rounds of the QC. Students in the $10-11^{\text {th }}$ grade can be members of both the IOI and CEOI team, younger students are only included in the CEOI team, and $12^{\text {th }}$-grade students only in the IOI team. This is to provide more opportunities for younger students for participating in international contests.

Students are invited to enter the contest based on their results in the national competition (OKTV and NT). In total, the competition is started with approximately 25-30 students in both the IOI and CEOI categories, about $70 \%$ of the participants are common. After the first two rounds, around 15 contestants advance in each category and after the second two rounds, only about 10 students per category compete in the last two rounds for the 4-4 places.

For the EJOI, we have a separate, shorter qualification contest, because we need to test different knowledge of the younger children. There are 2 rounds in this contest, each round has 3 problems for 3 hours. About 12-16 students are invited to the first round, and 6-12 participants advance to the second round, after which the 4 students of the EJOI team are selected based on their total score.

The Fig. 3 shows an overview of the system of competitions presented in this article. We included the trainings that help students in preparing for these contests. The next chapter provides more details about them.

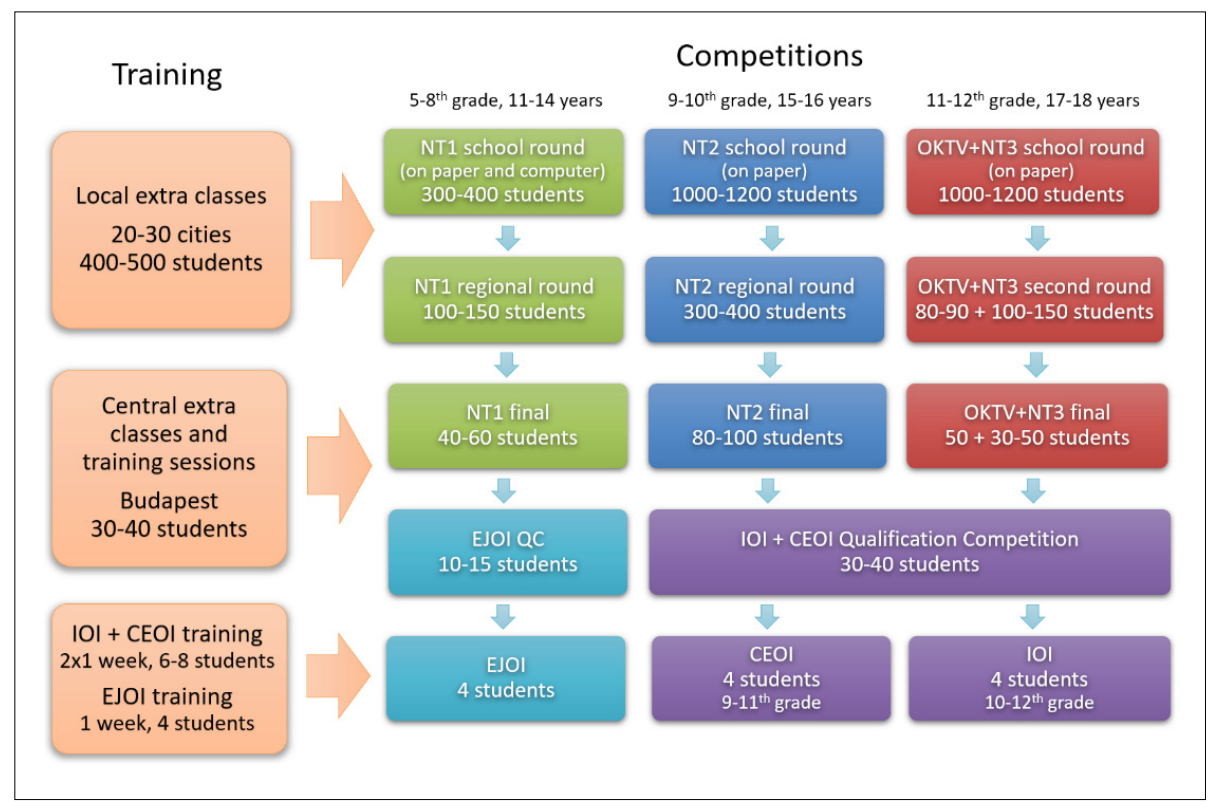

Fig. 3. Training and competitions in Hungary on the way to International Olympiads. 


\subsection{Training}

After the IOI and CEOI teams are selected, there is twice a one-week long training for team members. These are usually held in May and June, at ELTE, Budapest. We cover advanced topics of the IOI Syllabus and interesting tasks from past IOI and CEOI competitions. The training material is changing each year, customized to the skills and knowledge of the team members. The work is very intensive, 8 hours a day with a lunch break. Other students, who are not team members but have a good chance to qualify next year, are also welcomed to join the training.

The EJOI team has a separate one-week training, usually organized in July. The format is the same as above, but the topics are naturally different: graph algorithms, dynamic programming, greedy algorithms, recursion, backtrack, basic combinatorics. We also teach best practices and little tricks of every subject matter.

Hungarian students have been very successful in international competitions considering that we are a small country of 10 million people. The Fig. 4 shows the medals won at the IOI: a total of 13 gold, 31 silver and 44 bronze medals (data from IOI Statistics website).

Above we described the training specifically for the teams going to international Olympiads. There is also a countrywide system of talent education in Hungary, coordinated by the Talent Education Department of NJSzT and ELTE. The first stage is organized locally by volunteering schools in 20-30 cities across the country. They give extra courses to middle and high school children, who are interested in computer programming. The topics are flexible, teachers can conduct these classes according to their knowledge and interests. They are not limited to competitive programming, for example, there are some classes about robotics, application development, and a lot of introductory programming courses with block-based coding. ELTE and NJSzT provide education materials. The topics of the education materials include basic algorithmic patterns (sum, count, search, filter, maximum selection, sorting, merging, intersection, union, recursion) and introductory algorithmic strategies (greedy algorithms, backtracking, divide and conquer).

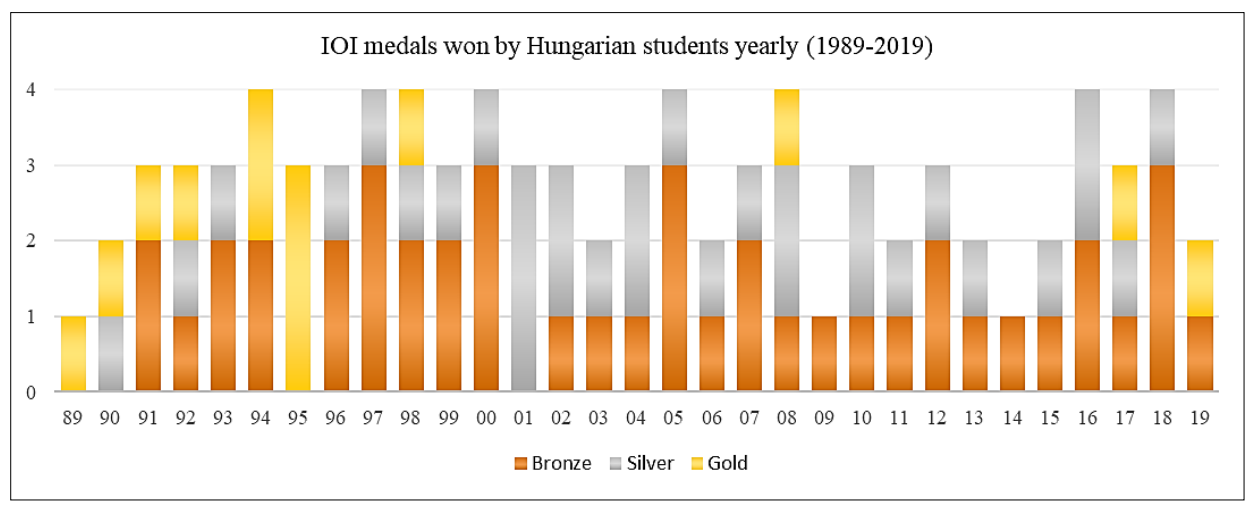

Fig. 4. Medal distribution of Hungarian students at the IOI yearly (1989-2019). 
As a continuation, there are 5 training sessions yearly for the most talented students of the country, held in Budapest by one of the authors, László Zsakó. Students can apply based on their teachers' recommendations. In these training sessions, the following topics repeat every two years: greedy algorithms, recursion, dynamic programming, trees and binary trees, graph algorithms, combinatoric algorithms, geometric algorithms, and simulation.

Additionally, there are some extra courses held by university students in selected schools in Budapest. The first author of the article is currently involved in one of them. The classes are bi-weekly and open for all talented students from the capital and other cities, too. We solve former IOI tasks and learn advanced algorithms and data structures, according to the level of the participants.

There are few cities apart from Budapest where some prominent teacher leads a selfdeveloped talent education system. The results of the programming competitions show the existence of such places. For example, the city of Nagykanizsa is providing numerous good contestants every year, due to the excellent work of Ágnes Erdősné Németh, who thereby became vice president of NJSzT recently. Other notable places of good programming education include Debrecen, Zalaegerszeg, Szatmárnémeti, and there are several individual teachers scattered in the country.

\section{Current Challenges and Plans}

Although there is a talent education network established in Hungary, on the highest level, the achievements of students rely on a local excellent teacher in very few places, or completely on their individual efforts. We would like to start a program focused on the most talented students countrywide, forming groups that stay together for years, organizing weekend camps, and online workshops for them. The bases of this program were outlined in (Nikházy, 2020). A similar system (Győri \& Juhász, 2017) was built in mathematics by The Joy of Thinking Foundation that we consider as a model. We want to put emphasis on creating a community. Currently, gifted students mostly meet only at the competitions. In our experience with the mathematics camps, personal connections play a big part in the engagement of learning at this very high level.

We also plan to start talent training programs focused on girls. The underrepresentation of women in IT is a well-studied topic worldwide. Unfortunately, Hungarian programming contests also show this phenomenon. With Hungary participating in the EGOI from its start in 2021, we are committed to encouraging girls to master programming. While we include girls in the above-mentioned talent programs, we would like to organize training specifically for girls, where more than half of participants are young ladies, and the rest of them are boys with similar knowledge level.

There is room for improvement in the competitions as well. The top contestants' knowledge level is getting higher year by year, and we, the scientific committee of the NT competition, try to keep up with it while maintaining the spirit and fairness of the contest. Since there are a wide variety of languages allowed, it is a challenge to create language-independent tasks, where the evaluation makes it possible to differentiate 
between the solutions according to their computational complexity with the same time limit for every language. It is not only our problem, but many other systems also face this issue. We are looking into solutions, we might consider language-dependent time limits. The current scoring system, which is based on individual test cases, also makes it hard to rate solutions according to their complexity, because sometimes only specially constructed tests detect the slowness of an algorithm. With a lot of other tests in place, a suboptimal solution can get almost full points. Scoring based on test groups is an option that we are looking into currently, but we also find it unfair to give no score to a solution that is correct for most of the test cases (Erdősné Németh \& Zsakó, 2018).

Finally, it is always our goal is to make programming competitions more popular in Hungary. We hope that our current and future work in talent education and community building will encourage more and more students to learn programming and participate in contests.

\section{References}

Erdősné Németh, Á., \& Zsakó, L. (2018). Grading Systems for Algorithmic Contests. Olympiads in Informatics, 12, 159-166. DOI:10.15388/ioi.2018.13

Győri, J., \& Juhász, P. (2017). An extra-curricular gifted support programme in Hungary for exceptional students in mathematics. In Teaching Gifted Learners in STEM Subjects (pp. 89-106). Routledge.

Manev, K., \& Yovcheva, B. (2017). First European Junior Olympiad in Informatics. Olympiads in Informatics, 11, 171-173. DOI:10.15388/ioi.2017.15

Nikházy, L. (2019). A Nemes Tihamér Programozási verseny témaköreiről készült syllabus. InfoDidact2019. Zamárdi, Hungary: Webdidaktika Alapítvány.

Nikházy, L. (2020). A Problem-based Curriculum for Algorithmic Programming. Central-European Journal of New Technologies in Research, Education and Practice, 2(1), 76-96. DOI:10.36427/CEJNTREP.2.1.399

Szlávi, P., \& Zsakó, L. (2008). Módszeres programozás: programozási tételek. Budapest: ELTE Informatikai Kar.

Verhoeff, T. (2009). 20 Years of IOI Competition Tasks. Olympiads in Informatics, 3, 149-166.

Verhoeff, T., Horváth, G., Diks, K., \& Cormack, G. (2006). A proposal for an IOI Syllabus. Teaching Mathematics and Computer Science, 4(1), 193-216.

\section{Websites}

$\mathrm{B}^{3}$ - Bakonyi Bitfaragó Championship: https : //verseny .mik.uni-pannon.hu/

EGOI: https://egoi.org/

EJOI: http://ejoi.org/

e-Hód Competition: http://e-hod.elte.hu/

First $^{\circledR}$ LEGO $^{\circledR}$ League: https : //www . firstlegoleague.org/

IOI Statistics: https://stats.ioinformatics.org/

IOI Syllabus: https://ioinformatics.org/page/syllabus/12

Izsák Imre Gyula Complex Science Competition: http://www.zmgzeg. sulinet.hu/izsak/

Kozma László National Informatics Competition: https ://isze.hu/kozma-laszlo-orszagos-informatika-alkalmazoi-tanulmanyi-verseny/

LOGO National Informatics Competition: http://logo.inf .elte.hu/

Nemes Tihamér Informatics Competition: http://nemes.inf .elte.hu/

Neumann János Talent Search Software Product Competition: https://neumann.ibela.sulinet.hu/

NT Syllabus: https://github.com/niklaci/NT-Syllabus 
PENDroid High School Competition: https://pendroid.uni-pen.hu/

ProgRace Programming Contest: https: //prograce.hu/

Programmers' National Dusza Árpád Memorial Competition: https : //isze.hu/dusza-arpad-orszagosprogramozoi-emlekverseny/

Robot Programming National Team Contest: http://www.banyai-kkt.sulinet.hu/robotika/Robotverseny/robotverseny.html

Robot Sumo Competition: http://sagv.gyakg.u-szeged.hu/szumo/

Talent Education Department of NJSzT: http://tehetseg.inf .elte.hu/

The Joy of Thinking Foundation: https ://agondolkodasorome.hu/en/

World Robot Olympiad TM: https: //wro-association.org/

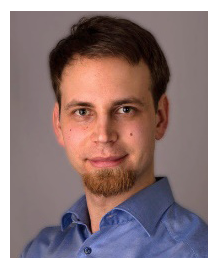

L. Nikházy is a Ph.D. student at the Department of Media \& Educational Informatics, Faculty of Informatics, Eötvös Loránd University in Hungary. His current research interest is computer programming talent education. He has been teaching mathematics in camps for gifted students since his early university years. After graduating from the Budapest University of Technology and Economics, and the Eötvös Loránd University, he started his career as a software engineer at Google. He gradually shifted to computer science education, and now devotes all his time to teaching talented children. He has been actively involved in organizing programming competitions and team coaching in Hungary in the past 3 years.

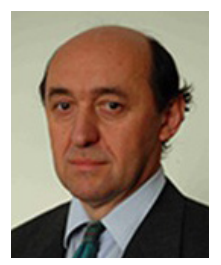

L. Zsakó Dr. is a professor at the Department of Media \& Educational Informatics, Faculty of Informatics, Eötvös Loránd University in Hungary. Since 1990 he has been involved in organizing programming competitions in Hungary, including the CEOI. He has been the deputy leader of the Hungarian team at International Olympiads in Informatics since 1989. His research interest includes teaching algorithms and data structures; didactics of informatics; methodology of programming in education; teaching programming languages; talent management. He has authored more than 68 vocational and textbooks, some 200 technical papers and conference presentations. 